\title{
Health care seeking patterns and out of pocket payments for children under five years of age living in Katchi Abadis (slums), in Islamabad, Pakistan
}

\author{
Aneeqa Rehman, Babar Tasneem Shaikh ${ }^{*}$ and Katrina A Ronis
}

\begin{abstract}
Background: Since 1990, Pakistan has faced an unprecedented rate of urbanization, thereby resulting in the uncontrolled proliferation of slums (Katchi Abadis) in all large cities. These areas lack the basic municipal services such as safe water supply, sanitation and waste collection. There is limited access to quality health care services, both curative and preventive. Therefore, communities living in katchi abadis are faced with health seeking challenges and catastrophic expenditure to pay for health care services (formal or informal).

Methods: This cross-sectional quantitative study was conducted in Islamabad, using a semi-structured questionnaire with mothers of children 5 years of age. There are 34 katchi abadis, 11 are recognized by the Capital Development Authority, out of which seven were included in the study. The calculated sample size was 207.

Main findings: Average household income was found to be Pak Rupee 10,000 (approx.US\$100) per month. Diarrhea, fever, common cold and cough were common illnesses among under 5 children. Approximately $43 \%$ of the mothers were illiterate and they preferred consulting a private doctor or a private dispenser in the katchi abadi. Mother's level of education was significantly associated with the type of health provider consulted. Majority had to spend out of pocket, while many either borrowed money from relatives or friends or sold a household item. Delay in seeking health care added to the out of pocket expense. The mean cost on child's treatment was approximately PkRs400 (approximately US\$4) for a single consultation.

Conclusion: There are several factors associated with health seeking behavior of mothers of children under the age of 5 years, living in the katchi abadis of Islamabad. The latter population group is one of the most vulnerable given their poor standard of living conditions. A multi-sectoral approach is needed to address the provision of basic amenities, the availability of safety nets to pay for health care is crucial to avoid catastrophic expenditure and the provision of community-based health promotion programs are essential to improve health seeking behaviors whilst simultaneously promoting and protecting health.
\end{abstract}

Keywords: Health seeking behavior, Out of pocket payment, Under 5 children, Katchi Abadis

\footnotetext{
* Correspondence: shaikh.babar@gmail.com

Health Systems \& Policy Department, Health Services Academy, Park Road, Islamabad, Chak Shahzad 44000, Pakistan
} 


\section{Background}

Many developing countries such as Pakistan struggle with low budget allocations to the health sector. In a low resource setting, the public health sector faces many challenges to provide quality health care to a variety of consumers. The private sector, which is perceived by some to be of superior quality, involves large out of pocket (OOP) expenditure [1], however the public sector also incurs a cost which for many is unaffordable Both the private and the public sector health care cost is pushing vulnerable population groups further into a poverty trap. The direct payments, (public or private) act as a barrier for poor people from seeking appropriate health care as early as possible. These vulnerable population groups forced to sell assets or borrow money to meet the catastrophic expenditure of health care i.e. spending a high proportion of non-subsistence expenditure on health $[2,3]$.

In developing countries, the poverty paradigm is shifting from rural to urban areas, the growth of over-crowded slums and shanty towns, characterized by unhygienic environmental conditions (e.g. uncollected waste, unsafe water, poor drainage and open sewers), expose the communities to various health problems. As a result of poor living conditions, the child morbidity and mortality rates are many times higher in slums compared to more privileged urban neighbourhoods; some rural settlements have better health indicators [4-6]. Decisions regarding health seeking patterns are dependent upon the type of illness and the cost of available services. For example, research suggests that in South Asia, health care seeking behaviour is low when consulting a formal health facility or a trained health care provider $[7,8]$. Alleviation of financial barriers is a top priority for policy makers to reduce child morbidity and mortality, due to the fact that financial barriers influence the health seeking behaviours of poor communities globally [9-14]. There are many factors involved that add to the cost of health care services incurred, and thus delay in treatment. Lack of trust and non-responsiveness on the first level care centers, and secondary and tertiary government hospitals compel the parents of under five children to bypass the government's primary health care services and go for expensive private hospitals, despite additional costs and time consumed in treatment $[15,16]$.

Pakistan's health system faces many challenges to improve the health indicators of its population. The poorly subsidized non-responsive public sector health system forces people to go for health care in the private sector, both formal and non-formal. Since the private sector primarily operates for profit, citizens have to pay large fees for consultations as well as for medicines, even for minor ailments [17]. In 2011-2012, the outlay of GDP for health was only $0.27 \%$ [18]; which is lower than all previous allocations [19]. This has resulted in $86.3 \%$ $84.48 \%$ OOP health expenditure, which is high by world standards, but also in the Eastern Mediterranean region (Table 1) [20]. Total health expenditures in Pakistan, $25.1 \%$ are made by general government. The private expenditures constitute $72 \%$ of total health expenditures in Pakistan, out of which 92\% are households' out-ofpocket (OOP) health expenditures. Development partners and donor organizations have 3\% share in total health expenditures [21]. There is no social health insurance system in the country and with rising poverty, many households are pushed to the level of catastrophic expenditure while utilizing healthcare [22].

Women and children under five years of age are the most susceptible to illnesses, and therefore need special and urgent medical attention. Since $80 \%$ of the people rely on private consultations at the first level of care in Pakistan, they ought to spend money for paying off the fee of doctor and for buying the medicines [23]. There are some regions were the social mobility of women is limited, and in combination with lower socioeconomic status living conditions, this leads to delayed medical consultation, and in some circumstances more expenses [24]. It is well established that household income is one of the major determinants in health care seeking behaviours $[25,26]$. There is a growing need to understand the broader determinants of health seeking behaviour to support and strengthen health systems within the local cultural context [27].

\section{Methodology}

a) Study area profile In Islamabad, there are 34 katchi abadis, 11 are recognized by the Capital Development Authority (CDA). The total population of slums in Islamabad is 88,437 . Seven katchi abadis with CDA allotted house numbers were included in the study [28].

b) Study design The study used a quasi-experimental design, using a cross-sectional community based survey, with a quantitative approach.

\begin{tabular}{|c|c|c|c|}
\hline $\begin{array}{l}\text { WHO worldwide } \\
\text { statistics }\end{array}$ & $\begin{array}{l}\text { Global } \\
2009^{*}\end{array}$ & $\begin{array}{c}\text { EMRO } \\
\text { countries 2009* } \\
\end{array}$ & $\begin{array}{c}\text { Pakistan } \\
\text { 2011-2012** }\end{array}$ \\
\hline $\begin{array}{l}\text { Total expenditure on } \\
\text { health as } \% \text { age of GDP }\end{array}$ & 8.5 & 4.2 & 0.27 \\
\hline $\begin{array}{l}\text { Private expenditure on } \\
\text { health as } \% \text { age of total } \\
\text { expenditure on health }\end{array}$ & 38.4 & 46.8 & 72 \\
\hline $\begin{array}{l}\text { OOP expenditure as } \% \\
\text { age of total expenditure } \\
\text { on health }\end{array}$ & 50.7 & 88.9 & 92 \\
\hline
\end{tabular}

*World Health Statistics 2012; **Pakistan Economic Survey 2011-12. 
c) Sampling technique Multistage sampling technique was utilised. In the first stage, legal slums (katchi abadis) in Islamabad were chosen as the study area, considering constraints such as time and resources, as per the sampling frame of CDA. In the second stage, proportional allocation of the calculated sample size to the identified slums was undertaken. In the third and last stage, simple random sampling using CDA sampling frame was undertaken considering our inclusion and exclusion criteria. Study participants were selected using simple random table, thereby giving them equal probability of selection. In this way, the size allocated to each of the selected katchi abadis was chosen. Use of simple random sampling reduced the chances of known and unknown biases.

d) Study population and selection criteria Those households with a child under the age of five years were selected from the identified slums, and from those households where a child under- 5 years of age had been sick and treated in the last month. Households having an acutely sick child were excluded from the study.

e) Sample size Sample size was calculated by using the formula for proportion: $\mathrm{n}=\frac{z^{2} p q}{d^{2}}$; which is valid where $\mathrm{z}^{2}=$ the abscissa of the normal curve that cuts off an area $\alpha$ at the tails $(1-\alpha$ equals the desired confidence level, e.g., 95\%), we took it 1.96; $d=$ is the desired level of precision, i.e. 0.05; $\mathrm{p}=$ the estimated proportion of an attribute that is present in the population; and $\mathrm{q}=1-\mathrm{p}$. The value for ' $\mathrm{z}$ ' is found in statistical tables which contain the area under the normal curve. According to World Bank 2011 OOP payment in Pakistan is 86.3\% [20]. The minimum sample size calculated is 207. Allowance for non-response was kept at $10 \%$ and was utilized during data collection. There was an ethical pressure too as some of the respondents conveyed the message to other households in vicinity and they wanted to respond to this research. A total of 252 respondents were included in the study and there were no refusals per se (Table 2).

f) Data collection

A semi-structured pre-coded questionnaire was used for data collection. This tool was developed after an extensive literature review on the health seeking behaviours and health services utilization trends in Pakistan, and some regional countries. Questionnaire and consent forms were translated in Urdu, before data collection commenced. The
Table 2 Sample selected from different slums, proportionate to their population

\begin{tabular}{lcc}
\hline Slum areas of Islamabad & Frequency & Percent \\
\hline Diplomatic enclave, Muslim Colony & 56 & $22.2 \%$ \\
G-8/1, Charles- Hansa Colony & 51 & $20.2 \%$ \\
G-7/2, Near 66 Quarters & 48 & $19.0 \%$ \\
G-7/1, Faisal Colony & 27 & $11 \%$ \\
F-7/4, France Colony & 35 & $13.9 \%$ \\
F-6/2, Near 100 Quarters & 25 & $9.9 \%$ \\
G-7/3, Allama lqbal Colony & 10 & $4 \%$ \\
Total & $\mathbf{2 5 2}$ & $\mathbf{1 0 0} \%$ \\
\hline
\end{tabular}

questionnaire was piloted and amended to ensure the questions were comprehensible. Questions were asked regarding the child's last illness or symptoms for which a treatment was sought; type of health care provider consulted; consultation fee; cost of medicines; distance to the health facility visited; cost of transport (if any); mode of arrangement of money; any budget set aside by the family for health; and willingness to participate in a health insurance program (if one introduced). This study was conducted from April to July 2012.

g) Data analysis SPSS version 16.0 was used for the descriptive analysis and the inferential analysis was carried out using chi-square test with cross-tabulation to assess any significant associations.

h) Ethical considerations This research was approved by the Institutional Review Board of the Health Services Academy, Islamabad. Verbal informed consent was obtained from the study participants after the researcher explained the purpose of the research. Anonymity and confidentiality of the study participants was maintained throughout the study. Dignity and respect for all the study participants was adhered to, throughout the research.

\section{Results}

\section{Socio-demographic characteristics}

The mean age of the respondents (primarily mothers of under 5 children) was $31 \pm$ SD 3 years. Approximately $72 \%$ of the study participants earned a monthly income ranging between PkRs7000-15000 (US\$65-145) per month. Fifty seven per cent $(57 \%)$ of the study participants were employed in temporary private jobs. Forty three per cent of the women had no education and $37 \%$ had primary level education. Two thirds (61\%) of the women had up to 4 children. 


\section{Illness reported among U5 children}

The reported illnesses for the under five year old children was as follows: Diarrhoea (35\%, fever of undiagnosed origin (34\%) common cold (11\%) and gastro-intestinal disorders $(8 \%)$.

\section{Type of health care provider consulted and why?}

The majority of study participants consulted a private health care provider, either a modern allopathic doctor or a dispenser (Figure 1). Government health care providers include doctors, dispensers and lady health workers (who provided home based primary health care). The reasons for choosing the health care provider varied largely for two types of health care providers consulted by the community. Local community consulted private doctors because of the proximity (92\%), their empathetic attitude (90\%) and the satisfaction with the treatment provided by them (64\%). Government health care providers who provide free consultation are consulted by $73 \%$ of the patients, and around one third of the mothers (33\%) expressed their satisfaction with the treatment from a government doctor, dispenser or a lady health worker. Data reveals that a significant association between the place of residence and type of health care provider consulted $(\mathrm{p}=0.00)$. Mother's educational status was also found to be strongly associated with type of provider consulted for U5 child's illness $(\mathrm{p}=0.01)$.

\section{Expenses incurred on treating the illness of U5 children and OOP trend}

The mean expense incurred on treatment for children under the age of five years and their illnesses was PkRs400 (approximately US\$4), though it ranges from PkRs100 to more than PkRs500 (as shown in Figure 2). A large majority (86\%) of the study participants had to bear this expense out of pocket, either by borrowing money from a neighbour or a relative (42\%); or by selling their household belongings (23\%).

Data shows strong statistical association between arrangement of money spent on U5 child's treatment and immediate consultation with the health provider $(\mathrm{p}=$ 0.00). Strong or significant statistical association was

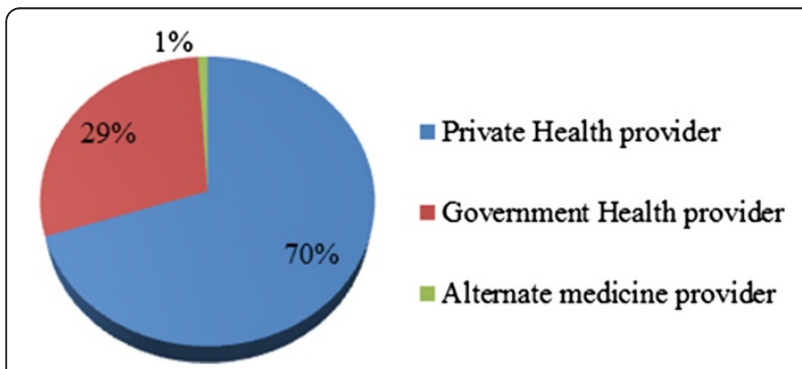

Figure 1 Type of health care provider consulted for treating under 5 children's illnesses.

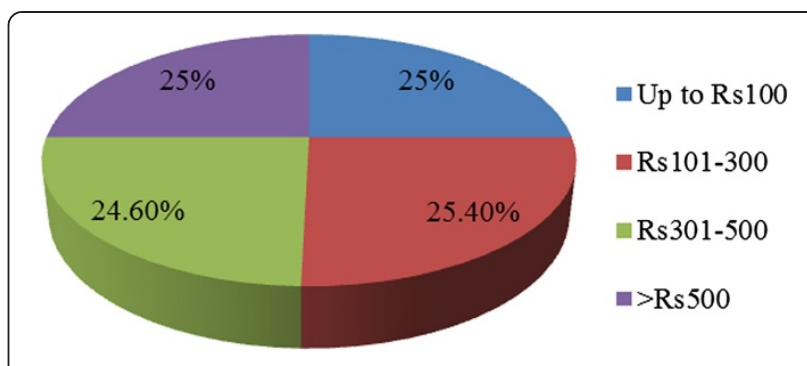

Figure 2 Expenses incurred for treating under 5 children's illnesses.

found between total expense on illness of under five children and type of health care provider $(p=0.00)$; where private providers' treatment was far more expensive. No significant statistical association was found between the expenses incurred and household income, place of residence, and gender of the sick child. When asked about the saving practices and willingness to put aside some money for such hard times, almost none of the study respondents reported on keeping such savings; however $48 \%$ showed their willingness to join a saving scheme, if introduced in their area.

\section{Suggestions by mothers for the better healthcare of U5 children}

Thirty seven per cent (37\%) of the study participants demanded or requested that a qualified doctor be posted in their vicinity on a full time basis. Free or subsidized medical services for children and pregnant women also emerged to be one of the demands (32\%). More than one third of the study participants did not know what to suggest for improving the financial safety net of health care provision.

\section{Discussion}

Health care seeking behaviours and patterns are dependent on a host of factors; amongst which the financial status of the household is a major determinant $[29,30]$. The results of this study validate the existing literature, hence reinforcing the association between family income and socioeconomic status of the household with the choice of health care provider to be consulted. OOP payments were incurred by a large proportion of the study population, similar to national data $[21,31]$. In our study area, significant number of population lives just above the poverty line. The minimum wages declared by the Government of Pakistan are PkRs9000 (approximately US\$91) per month. Living on limited budgets may have contributed to in the delay in health care seeking behaviour for the mothers of sick children [24]. Our study confirms that immediate consultation with a health care provider is strongly associated with the disposable income of the family at the time of the child's illness. 
The preference by the study participants to consult a private healthcare provider, is a major finding which reflects findings of the Pakistan Demographic \& Health Survey 2007-08 [32]. Due to the fact that private medical care is relatively expensive, people believe that they should save some money for such catastrophic expenditures related to episodes of illness. Such catastrophic expenses push families into ultra-poverty conditions [33]. The Capital Administration Authority must be sensitised to such findings to plan for the provision of safety nets or a social protection mechanism to poor families of slum dwellings living in Islamabad, especially with respect to their health expenses. Empowering women through education and access to health information and great employment opportunities is an effective conduit in promoting appropriate and timely health care seeking behaviour for children [26,34]. In the absence of such interventions, there is a strong likelihood that such health inequities will further increase and will make this vulnerable population suffer even more.

\section{Conclusion}

The high OOP expenditures (or catastrophic expenditures) on child health care seeking behaviour has serious implications in terms of pushing the disadvantaged communities of katchi abadis into cyclical poverty wheel. A safety net in the form of vouchers, cash transfers or community based health insurance is crucial to address such glaring inequalities and inequities in health care seeking behaviour. As an immediate intervention improving the quality of services in the government dispensaries and having a 24/7 emergency care available could reduce the financial burden on the parents of children under the age of five years, living in the fragile habitat of the katchi abadis.

\section{Competing interests}

The authors declare that they have no competing interests.

\section{Authors' contributions}

AR conceived the study, designed methodology, performed the data collection and drafted the initial manuscript. BTS supervised the study design development, data collection, preliminary write up, and contributed to all subsequent drafts. KAR suggested on write up, syntax, revision of drafts and finalization of manuscript by adding intellectual content to the paper. All authors read and approved the final draft.

\section{Acknowledgement}

We are grateful to the Health Services Academy, Islamabad for providing logistic and financial support for conducting the study. We are indebted to the respondents of the study for their precious time and valuable information without which this study could not have been materialized.

Received: 15 November 2013 Accepted: 11 April 2014

Published: 16 April 2014

\section{References}

1. Mazilli C, Davis A: Health Seeking Behavior in Somalia-Literature Review New York: UNICEF \& European Union. Report 10; 2009.
2. Falkingham J: Poverty, out of pocket payments and access to health care: evidence from Tajikistan. Soc Sci Med 2004, 58(2):247-258.

3. Patil SS, Berad AS, Angadi MM: A study to assess catastrophic household expenditure on childhood illness in an urban slum in Bijapur. Indian J Community Med 2009, 34(4):335-337.

4. More NS, Bapat U, Das S, Barnett S, Costello A, Fernandez A, Osrin D: Inequalities in maternity care and newborn outcomes: one-year surveillance of births in vulnerable slum communities in Mumbai. Int J Equity Health 2009, 8:21.

5. Fotso GC: Child health inequalities in developing countries: differences across urban and rural areas. Int J Equity Health 2006, 5:9.

6. Giashuddin MS, Hosain MM: Factors associated with child health in urban areas of Bangladesh. Bangladesh J Sci Res 2011, 24(2):145-154.

7. Herbert HK, Lee AC, Chandran A, Rudan I, Baqui AH: Care seeking for neonatal illness in low- and middle-income countries: a systematic review. PLOS Med 2012, 9(3):e1001183.

8. Steinhardt LC, Waters H, Rao KD, Naeem AJ, Hansen P, Peters DH: The effect of wealth status on care seeking and health expenditures in Afghanistan. Health Policy Plan 2009, 24(1):1-17.

9. Ridde $V$, Diarra A: A process evaluation of user fees abolition for pregnant women and children under five years in two districts in Niger (West Africa). BMC Health Serv Res 2009, 9:89.

10. Srivastava NM, Awasthi S, Agarwal GG: Care-seeking behavior and out-of-pocket expenditure for sick new-borns among urban poor in Lucknow, Northern India: a prospective follow-up study. BMC Health Serv Res 2009, 61:9.

11. Page AL, Hustache S, Luquero FJ, Djibo A, Manzo ML, Grais RF: Health care seeking behavior for diarrhoea in children under 5 in rural Niger: results of a cross-sectional survey. BMC Public Health 2011, 11:389.

12. Khun S, Manderson L: Poverty, user fees and ability to pay for health care for children with suspected dengue in rural Cambodia. Int J Equity Health 2008, 7:10.

13. Ndugwa RP, Zulu EM: Child morbidity and care-seeking in Nairobi slum settlements: the role of environmental and socio-economic factors. J Child Health Care 2008, 10(12):314-328.

14. Sverdlik A: Ill-health and poverty: a literature review on health in informal settlements. Environ Urban 2011, 1(23):123-155.

15. Kallander K, Hildenwall H, Waiswa P, Galiwango E, Peterson S, Pariyo G: Delayed care seeking for fatal pneumonia in children aged under five years in Uganda: a case-series study. Bull World Health Organ 2008, 86(5):332-338

16. Kahabuka C, Kvale G, Moland KM, Hinderaker SG: Why caretakers bypass primary health care facilities for child care - a case from rural Tanzania. BMC Health Serv Res 2011, 11:315.

17. Shaikh BT: Health Care System in Pakistan. In Health Care Systems: A Global Survey. Edited by Rout HS. New Delhi: New Century Publications; 2011:434-454.

18. Ministry of Finance: Economic Survey of Pakistan 2011-2012. Health and Nutrition; 2012. http://www.finance.gov.pk/survey/chapter_12/11HealthAndNutrition.pdf [accessed on 13th April 2013].

19. Ahmed J, Shaikh BT: An all-time low budget for health care in Pakistan. J Coll Physicians Surg Pak 2008, 18(6):388-391.

20. World Bank: Out-of-pocket health expenditure. \% of private expenditure on health. http://data.worldbank.org/indicator/SH.XPD.OOPC.TO.ZS [accessed on 13th September 2013].

21. Pakistan Bureau of Statistics: National Health Accounts Pakistan 2007-2008; 2009. http://www.pbs.gov.pk/sites/default/files/national_accounts/national\% 20health\%20accounts/National_Health_Account_2007-08.pdf [accessed on 15th August 2013]

22. Abrejo FG, Shaikh BT: Social Health Insurance: can we ever make a case for Pakistan? J Pak Med Assoc 2008, 58(5):267-270.

23. Shaikh BT, Hatcher J: Health seeking behavior and health services utilization in Pakistan: challenging the policy makers. J Public Health (Oxf) 2005, 27(1):49-54.

24. Shaikh BT, Haran D: Treating common illnesses among children under 5 years: a portrayal of health seeking behaviors and practices in the Northern areas of Pakistan. World Health Popul 2011, 12(4):24-34.

25. Janjua NZ, Khan MI, Usman HR, Azam I, Khalil M, Ahmad K: Pattern of health care utilization and determinants of care-seeking from GPs in two districts of Pakistan. Southeast Asian J Trop Med Public Health 2006, 37(6):1242-1253. 
26. Shaikh BT, Hatcher J: Health seeking behaviour and health services utilization trends in national health survey of Pakistan: what needs to be done? J Pak Med Assoc 2007, 57(8):411-414.

27. Shaikh BT, Haran D, Hatcher J, labal Azam S: Studying health-seeking behaviours: collecting reliable data, conducting comprehensive analysis. J Biosoc Sci 2008, 40(1):53-68.

28. Akhtar Hameed Khan Resource Center: Shelter for the poor: Legislation and Enforcement: A Case Study of Islamabad. Available at: http://www.ahkrc.net. pk/assests/pdf/Housing-for-the-poor.pdf [accessed on 10th April 2013].

29. Shaikh BT, Haran D, Hatcher J: Where do they go, whom do they consult, and why? Health seeking behaviours in the Northern areas of Pakistan. Qual Health Res 2008, 18(6):747-755.

30. D'Souza RM: Role of health-seeking behaviour in child mortality in the slums of Karachi, Pakistan. J Biosoc Sci 2003, 35(1):131-144.

31. Malik MA, Azam SI: Socio-economic determinants of household out-of-pocket payments on healthcare in Pakistan. Int J Equity Health 2012, 11:51.

32. National Institute of Population Studies \& Macro International: Pakistan Demographic \& Health Survey 2006-07. Islamabad: Government of Pakistan; 2008.

33. GTZ-ILO-WHO: Consortium on Social Health Protection in Developing Countries. Eschborn; 2007. http://www.socialhealthprotection.org/drucken. php?druck=about_us.php (accessed on 18th August 2013).

34. Aga Khan Development Network: Microfinance for Women in Northern Pakistan. AKDN Publications; 2007. http://www.akdn.org/publications/case_study_akam_ women_pakistan.pdf (accessed on 12th September 2013).

doi:10.1186/1475-9276-13-30

Cite this article as: Rehman et al:: Health care seeking patterns and out of pocket payments for children under five years of age living in Katchi Abadis (slums), in Islamabad, Pakistan. International Journal for Equity in Health 2014 13:30.

\section{Submit your next manuscript to BioMed Central and take full advantage of:}

- Convenient online submission

- Thorough peer review

- No space constraints or color figure charges

- Immediate publication on acceptance

- Inclusion in PubMed, CAS, Scopus and Google Scholar

- Research which is freely available for redistribution 